\title{
Pharmaceutical patents, $R \& D$ incentives and access to new drugs: new ways of progress at the crossroad
}

\author{
Fernando Antoñanzas • Carmelo Juárez-Castelló • \\ Roberto Rodríguez-Ibeas
}

Published online: 24 June 2011

(C) Springer-Verlag 2011

Patents are defined as a right granted to innovators by governments for the exclusive production and marketing of an innovation for a limited period of time. Patent owners enjoy a legal monopoly. Patents rights have traditionally been considered a good mechanism to provide incentives to innovate as it allows innovators to obtain monopolistic benefits that compensate the R\&D expenditures. In the case of the pharmaceutical industry, as imitation of new drugs is relatively easy and it is difficult to keep the 'first mover' advantage in the market, it seems that the patent system is the only mechanism to incentive the innovative activity.

\section{Some side effects of patents}

A manufacturer of a patented drug benefits from exclusive rights as long as there exists a willingness to pay the high monopoly price. Thus, the patent system provides incentives for R\&D activity in drugs that satisfy the demand of the developed countries, where patients have a sufficiently high income or where private or public insurance systems pay the pharmaceutical bill. As a result, many pharmaceutical innovations are not accessible for poor segments of the population in developed countries-lacking public or private insurance coverage- or for the vast majority of the population in less developed countries. Moreover, the pharmaceutical industry does not have incentives to spend resources in developing drugs for rare diseases (not sufficiently large market) and for diseases mostly prevalent in poor countries (unaffordability).

F. Antoñanzas $(\bowtie) \cdot C$. Juárez-Castelló · R. Rodríguez-Ibeas Department of Economics and Business, University of La Rioja, C/La Ciguena 60, 26004 Logrono, Spain e-mail: fernando.antonanzas@unirioja.es
Furthermore, not every innovation has the same therapeutic value, no matter whether they are excellent products in terms of relative efficacy and safety as compared to existing agents, simple imitations (me-toos), slight variations of existing drugs (line extensions) or new applications of a known drug (second indication patents). However, all of them are protected by the patent system. Additionally, some drugs with no therapeutic value are protected by several related patents, besides the one granted for the active principle, to generate entry barriers to potential competitors in that field.

Grabowski and Wang [7] reported that worldwide and for the period 1982-2003, 919 new chemical ingredients were introduced, being only 115 of them first in class, i.e., strictly new. Hong et al. [8] showed that only $15 \%$ of the 1,035 new drugs approved by the US Food and Drug Administration from 1989 through 2000 were innovative drugs. For instance, in 2002, out of 78 new drugs approved by the FDA, only 17 contained new active principles and barely seven were considered to improved existing drugs. Furthermore, between 1998 and 2002, as reported by Angell [1], 415 new drugs were approved by FDA and only $14 \%$ of them were innovations.

In order to guarantee the flow of high benefits, pharmaceutical firms reinforce their competitive position by spending enormous amount of resources in marketing activities. In this sense, Gagnon and Lexchin [6] showed that pharmaceutical companies spent in promotion and marketing activities twice as they did in R\&D $(57,500$ million USD versus 29,500 million USD in the USA for the year 2004).

In developed countries, the social welfare systems guarantee access to drugs. Drugs are considered merit goods whose consumption must be guided by equity and necessity considerations instead of willingness to pay and 
demand criteria. Coverage levels and universal access vary across countries, being quite generous in most of them, what poses a threat to the financial sustainability of their health systems.

In poor countries, the capacity to pay for drugs is inexistent and the governments do not have the resources needed to implement a public health system to cope with the monopolistic prices of the pharmaceutical innovations. Moreover, due to economic (e.g. lack of adequate hygienic infrastructures) or geographical reasons, there are specific diseases (malaria, dengue, chagas,...) that do not exist in developed countries and for which the pharmaceutical industry have not developed drugs due to the lack of economic incentives. Both issues raise different analytical challenges. The first one is directly related to the patent system. If there would be no patent system, cheap drugs could be produced and poor countries would be more able to afford the treatments. Drugs access would be available to those who need them, regardless of income. The second one reflects the incapacity of the patents system to guide the innovative activity according to the nature of drugs as merit goods.

The debate about patents has been revisited since the end of the last century. Although patents regulation is a national regulatory issue that has also domestic effects, the signature of the TRIP agreement by the World Trade Organization (WTO) in 1994 [13] has implied the generalization of a strong patent system (that defends and protects innovations in a wide sense) in almost all the countries in the world. This agreement has had important consequences on the accessibility to some new drugs. Due to the fact that the generalization of the patent system was not free of controversies and difficulties, the WTO adopted the Doha's Declaration on the relationship between TRIP and public health in 2001 [14]. This Declaration assumed that international property agreements must be interpreted and applied in such a way that would support the rights of the countries to protect their public health and to promote the general access of the population to new drugs. In order to achieve these goals, the right to apply TRIP agreements under flexible conditions is reinforced-e.g., compulsory licensing due to public health reasons and the EU 'Bolar' directive to speed the introduction of generics.

However, the most developed countries such as the USA and UE have used bilateral agreements with less developed countries to impose the so called TRIP-plus conditions that oblige to the latter countries to regulate in favour of the strong patent system and to self-impose limitations to the use of the more flexible conditions allowed by Doha's Declaration.

\section{Recent institutional steps for a change}

The solutions for the less developed countries suggested by the World Health Organization as well as by another international institution-see Correa [3] - aim to incorporate the assessment of the therapeutic utility to discourage minor innovations. In this sense, there is a trend to manage the intellectual property so that the patent regulatory process granted protection to only highly therapeutic value drugs.

Regarding to less developed countries, one policy supported by all the actors is the intensive use of exceptions and flexibility conditions of Doha's Declaration, especially, compulsory licensing. Danzon and Towse [5] suggested several measures as volunteer licensing through the 'patent pool', which allows to license pharmaceutical patents in an open way to developing countries, speeding generic competition and other transfers of technology, which would allow the access to drugs at the lowest price in a competitive market. These authors also recommended the pharmaceutical companies to adopt price discrimination policies -charging higher prices in developed countries and lower ones in less developed countries.

Given that R\&D and production of drugs is mostly made by the pharmaceutical industry and acknowledging that globally this market system fails to provide drug access to all patients who need it; there are some initiatives to promote a more active involvement of governments and international institutions on this area. As an example, the Global Strategy and Plan of Action on Public Health, Innovation and Intellectual Property (GSPOA) [2], a World Health Organization initiative, targets the identification and assessment of priorities dealing with $\mathrm{R} \& \mathrm{D}$ referred to diseases prevalent among the developing countries. This GSPOA also promotes incentives to this kind of R\&D, as well as the improvement of the innovative capacity of developing countries through transfers of technology. It seems that this would be a way to cope with the neglected diseases in poor countries.

The implementation of all these initiatives depends on the willingness to change or on the adoption of more active practices of corporative social responsibility of the pharmaceutical industry and on the existence of private and public donors. So far, pharmaceutical firms have been reluctant to modify their behaviours, and governments of developed countries have not applied the flexibility mechanisms of the Doha's Declaration. As a result, there exists scepticism around the outcomes of these initiatives.

At the same time, it does not seem that the suggested alternatives to promote R\&D on the neglected diseases are easy to implement raising some concerns even among experts on this area [4]. 
New initiatives for making drugs more accessible for all

Assuming all these aforementioned difficulties, other kind of ideas has been offered for discussion. One of the most appealing is based on prizes, Stiglitz [12] and Love and Hubbard [10]. This approach aims to incentive innovation through competition by separating the cost of $R \& D$ and the price of the drug. The prize system would reward the innovations based on their positive impact on health. In this way, patents would be considered as a right to be rewarded via prizes rather than a right to exclude competition by monopolistic power-as currently-with the consequences of high prices.

Proposals of this type require further implementation practicalities to become fully feasible. For instance, who determines the size of the prize, who is eligible to win and whether the winner takes all or just a proportion of the prize, and how the prize is funded, among others.

The Advance Market Commitments, as suggested by Kremer and Glennerster [9] and later adopted by the Global Alliance for Vaccines and Immunisation, and the World Bank, are a new measure to promote the innovations for research in health fields without a clear profitable market. They consist of ex-ante commitments to fund through donations the new agent once it has been developed and market purchases keep low due to affordability problems of patients. The first experience of this policy was signed by 5 countries and Bill and Melinda Gates Foundation in 2007.

Finally, it deserves to be mentioned the Priority Review Vouchers (suggested by Ridley et al. [11] and later adopted by the Food and Drug Administration of the USA, in the year 2008) that provide incentives to invest in drugs for neglected tropical diseases. Companies that obtain approval for a treatment of a neglected disease are given a transferable voucher that allows them a priority review process for the authorisation of another agent.

\section{Which is the future we want?}

In summary, all these new proposals highlight the idea that the current patent system does not properly provide incentives for the innovation in really needed agents (mainly for highly prevalent diseases in developing countries and for rare diseases in developed countries) but rather promotes R\&D decisions based mostly on profitability leaving aside public health considerations. This behaviour leads to spend resources in overcrowded drug markets of developed countries with similar agents for the same indication at usually higher prices.

A modification of the current patent paradigm is needed if we, as a society, think in a global perspective with regard to human health. This challenge has to be carefully addressed and agreed by the partners, looking for a compromise between the need of $R \& D$ in innovative drugs and the right of the drug industry to obtain a fair return for its investments. Despite the importance of the issue at hand, we remark that we have found few references in the literature analysing the possibilities of a change, most of them being partial solutions to the general problem. It is not only a question of waiting for the patent expiration of an innovative drug already marketed at high prices in rich countries, as someone believes, to make it accessible for the people in less developed countries, but it is also a question of not having a drug to treat a high prevalent disease because the patent system does not promote R\&D in such a field of neglected diseases. The solution keeps waiting.

\section{References}

1. Angell, M.: The truth about the drug companies. How they deceive us and what to do about it. Random House, New York (2004)

2. Commission on Intellectual Property Rights, Innovation and Public Health: Public health, innovation and intellectual property rights. World Health Organization, Geneva (2006). Available at www.who.int

3. Correa, C.: Guidelines for the examination of pharmaceutical patents: developing a public health perspective - a working paper. ICTSD, WHO, UNCTAD (2006)

4. DiMasi, J.A., Grabowski, H.G.: Should the patent system for new medicines be abolished? Clin. Pharmacol. Ther. 82(5), 488-490 (2007)

5. Danzon, P.M., Towse, A.: Differential pricing for pharmaceuticals: reconciling access, $R \& D$ and patents. Int. J. Health Care Finance Econ. 3, 183-205 (2003)

6. Gagnon, M.A., Lexchin, J.: The cost of pushing bills: a new estimate of pharmaceutical promotion expenditures in the United States. PLoS Med. 5(1), 29-33 (2008)

7. Grabowski, H.G., Wang, Y.R.: The quantity and quality of worldwide new drug introductions, 1982-2003. Health Aff. 25(2), 452-460 (2006)

8. Hong, S.H., Shepherd, M.D., Scoones, D., Wan, T.: Product-line extensions and pricing strategies of brand-name drugs facing patent expiration. J. Manag. Care Pharm. 11(9), 746-754 (2005)

9. Kremer, M., Glennerster, R.: Strong medicine: creating incentives for pharmaceutical research on neglected diseases. Princeton University Press, Princeton (2004)

10. Love, J., Hubbard, T.: The big idea: prizes to stimulate R\&D for new medicines (2007). www.keionline.org/misc-docs/bigideaprizes.pdf

11. Ridley, D., Grabowski, H., Moe, J.: Developing drugs for developing countries. Health Aff. 25(2), 313-324 (2006)

12. Stiglitz, J.E.: Making globalization work. WW Norton, New York (2006)

13. WTO: Agreement on trade-related aspects of intellectual property rights (1994). Available at www.wto.org

14. WTO: Declaration on the TRIPS agreement and public health (WT/MIN(01)/DEC/2) (2001). Available at www.wto.org 